\title{
First report of the presence of Vibrio vulnificus in the Gulf of Gdansk
}

\section{Monika Kurpas $^{1}\left(\mathbb{D}\right.$, Małgorzata Michalska $^{1}{ }^{\oplus}$, Arkadiusz Zakrzewski $^{2}{ }^{\oplus}$, Katarzyna Zorena $^{1}{ }^{\oplus}$}

\author{
${ }^{1}$ Department of Immunobiology and Environmental Microbiology, Medical University of Gdansk, Poland \\ ${ }^{2}$ Department of Industrial and Food Microbiology, Faculty of Food Science, University of Warmia and Mazury in Olsztyn, Poland
}

\begin{abstract}
Background: Vibrio infections are becoming more frequent in the Baltic Sea region, which is caused by an increase in the sea surface temperature. Climate change creates the conditions for the emergence of new environmental niches that are beneficial for Vibrio spp., especially in the summer months. Vibrio vulnificus, which causes wound infections and septicaemia, represents a particularly dangerous species of Vibrio spp. There are numerous publications on the prevalence of $\mathrm{V}$. vulnificus in various regions of the Baltic Sea, but there is a lack of such data for the Polish coast. This prompted us to conduct a pilot study into the prevalence of the bacteria in the Gulf of Gdansk. The study aimed to detect Vibrio spp. in the coastal waters and the wet sand at the beaches and bathing areas in the Gulf of Gdansk.

Materials and methods: During the period from June $16^{\text {th }}$ to September $23^{\text {rd }} 2020,112$ samples of seawater and 105 samples of wet sand were collected at 16 locations along the coast of the Gulf of Gdansk and $\mathrm{Hel}$ peninsula. Isolation of Vibrio spp. was conducted by filtering method and the isolated bacteria was cultured on CHROM agar Vibrio and TCBS agar. Final genus identification was performed by the MALDI TOF technique.

Results: In the present study, 10 isolates of Vibrio spp. were obtained from seawater and wet sand samples collected in the Gulf of Gdansk and Hel peninsula coast. Three of the isolates were identified as V. vulnificus; the presence of the species was confirmed in the seawater samples which had been collected in Hel (1 isolate), Jastarnia ( 1 isolate), and Chalupy ( 1 isolate). One strain of Vibrio alginolyticus was isolated from the seawater sample collected in Hel. Moreover, identification was incomplete for 6 of the isolated strains, these were identified as Vibrio cholerae/mimicus These strains were collected in Jastarnia (1 isolate), Kuznica (1 isolate), Gdansk-Brzezno (1 isolate), Puck (2 isolates), Chalupy (1 isolate).

Conclusions: Our preliminary research study confirmed the presence of potentially pathogenic V. vulnificus in the Gulf of Gdansk in the summer months. Therefore, further monitoring of the presence of Vibrio spp. in the Baltic coast area is necessary.
\end{abstract}

(Int Marit Health 2021; 72, 4: 247-251)

Key words: Gulf of Gdansk, Vibrio, seawater, wet sand, marine environment

\section{INTRODUCTION}

Vibrio spp. are widespread in the estuaries and coastal areas of warmer climates (South Asia, South America, Africa, and the Mediterranean Sea). The disturbing fact is that the bacteria are more and more frequently found in the Baltic Sea, which may be associated with global warming $[1,2]$.
Three of the Vibrio genus (Gram-negative, curved-rod shape) pathogens are dangerous to humans; these include: $V$. cholerae, V. parahaemolyticus, and V. vulnificus. Rising water temperatures are a key factor contributing to the creation of new niches for Vibrio spp. [3, 4]. Studies carried out by Böer et al. [4] in the waters off the German coast on North Sea

Monika Kurpas, PhD, Department of Immunobiology and Environmental Microbiology, Medical University of Gdansk, ul. Dębinki 7, 80-211 Gdańsk, Poland,

e-mail: monika.kurpas@gumed.edu.pl

This article is available in open access under Creative Common Attribution-Non-Commercial-No Derivatives 4.0 International (CC BY-NC-ND 4.0) license, allowing to download articles and share them with others as long as they credit the authors and the publisher, but without permission to change them in any way or use them commercially. 
have shown the temperature as the main factor supporting the prevalence of $V$. vulnificus. Interestingly, these studies also showed that $V$. vulnificus frequently occurs in the Ems and Weser estuary, which suggests that lower salinity may also have an impact on prevalence of these bacteria [5]. Warm $\left(>18^{\circ} \mathrm{C}\right)$ and low salinity $(<2.5 \% \mathrm{NaCl})$ waters offer optimal functioning conditions for the growth of these bacteria. As was already mentioned, Vibrio spp. may also be used as a climate change warning indicator [6]. It has been suggested that the Baltic Sea may become a more favourable environment for these bacteria, especially in the summer months, near the estuaries and in coastal waters [6]. The mean temperature of the Baltic Sea ranges from $-10^{\circ} \mathrm{C}$ to $17^{\circ} \mathrm{C}$, depending on the region. For the last 29 years (1990-2018) the annual mean sea surface temperature of the Baltic Sea was the highest in 2014 and $2018\left(9^{\circ} \mathrm{C}\right)$. While the lowest annual mean sea surface temperature was recorded in $1996\left(6^{\circ} \mathrm{C}\right)$. Moreover, the analysis shows that the linear trend of warming was $0.59^{\circ} \mathrm{C} /$ decade in the analysed period (1990-2018) [7]. It is estimated that global warming may have a significant impact on the prevalence of Vibrio spp. in the Baltic Sea region. The Baltic Sea is also characterised as a brackish environment because of its low salinity, which is associated with the presence of estuaries of large rivers (Vistula and Oder) and limited water influx from the oceans [8].

A growing number of infections caused by Vibrio present in the waters of the Baltic Sea is worrying $[9,10]$. However, it is difficult to estimate the scale of the problem as there is no obligation to report cases caused by Vibrio spp. In fact, most European countries do not provide testing for these pathogens [2]. An increasing prevalence of Vibrio spp., which is considered a tropical pathogen, has led us to look more closely at the problem and to monitor the spread of Vibrio spp. in the Gulf of Gdansk. Our research is a pilot study which is planned as part of a larger research programme conducted by the Department of Immunobiology and Environmental Microbiology, Faculty of Health Sciences, Medical University of Gdansk, Poland [11].

\section{SAMPLING SITES}

MATERIALS AND METHODS

Samples were collected at 16 locations along the Gulf of Gdansk (1. Gdansk-Brzezno - gate 52; 2. Gdansk-Jelitkowo - gate 66; 3. Sopot - gate 43; 4. Sopot - gate 19; 5. Gdynia-Orlowo; 6. Gdynia - city beach; 7. Puck; 8. Wladyslawowo - gate 2; 9. Chalupy - Gulfside; 10. Chalupy - gate 18; 11. Kuznica - Gulfside; 12. Kuznica - gate 31; 13. Jastarnia - Gulfside; 14. Jastarnia - gate 48; 15 . Hel -Gulfside; 16. Hel - gate 64). The sampling was performed 7 times in the period from June $16^{\text {th }}$ to September $23^{\text {rd }}$ 2020. The sampling sites are presented in Figure 1. The

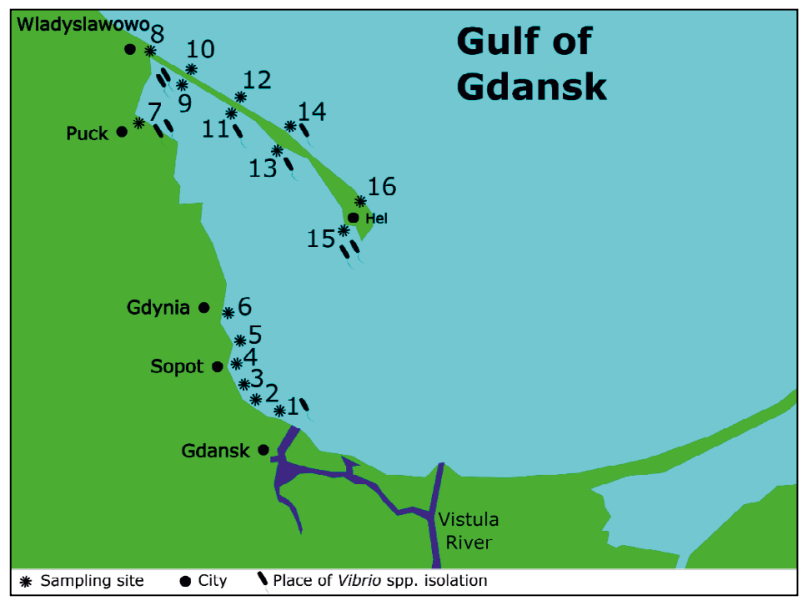

Figure 1. Sampling sites: 1. Gdansk-Brzezno - gate 52; 2. Gdansk-Jelitkowo - gate 66; 3. Sopot - gate 43; 4. Sopot - gate 19; 5. Gdynia-Orlowo; 6. Gdynia - city beach; 7. Puck; 8 . Wladyslawowo - gate 2; 9. Chalupy - Gulfside; 10 . Chalupy - gate 18; 11. Kuznica-Gulfside; 12. Kuznica - gate 31; 13. Jastarnia - Gulfside; 14. Jastarnia - gate 48; 15. Hel -Gulfside; 16. Hel - gate 64

sampling sites had been chosen to give us the opportunity to assess multiple bathing sites in the Gulf of Gdansk and along the coastal area of the Hel peninsula. Seawater and wet sand samples were taken at 2-week intervals between 5 and 12 a.m. Due to the characteristics of the shoreline, no sand samples were taken at point 9: Chalupy-Gulfside.

\section{WATER SAMPLES}

Sampling. A total of 112 seawater samples from the Baltic Sea were tested for the purpose of the present study. The water samples were taken at all 16 sampling sites (Fig. 1); approximately $0.5 \mathrm{~L}$ of seawater (taken at $1 \mathrm{~m}$ from the coastline and $20-30 \mathrm{~cm}$ below the water surface) was collected into aseptic bottles. A similar sampling method was used by researchers from the Department of Environmental Protection and Hygienic Transport [11]. The data on the water temperature at the sampling site was obtained from available online databases, and was established based on the longitude and latitude position of the sampling site. The data were obtained at 8 a.m. local time (e.g. SatBaltyk) [12]

Isolation and identification. All samples were transported directly from the sampling sites to the laboratories. The isolation was performed on the day of collection. Seawater $(50 \mathrm{~mL}$ ) was filtered using $0.22 \mu \mathrm{m}$, white, gridded $47 \mathrm{~mm}$ filters (Millipore, Merck; Germany). The filters were applied to the CHROM agar Vibrio (CHROMagar, France) to pre-differentiate the obtained microorganisms. Chromogenic agar with filters was incubated at $37^{\circ} \mathrm{C}$ for $18-24$ hours (POL-EKO APARATURA, Poland). Bacteria of the genus Vibrio that grow on the chromogenic medium exhibit a differentia colony colour (V. parahaemolyticus - mauve, V. cholerae/ 
N. vulnificus - turquoise blue). In the next step, the characteristic colonies from the Vibrio chromogenic agar were transferred onto chromogenic thiosulfate-citrate-bile salts-sucrose (TCBS) medium (Merck, Germany) and incubated at $37^{\circ} \mathrm{C}$ for $18-24$ hours (POL-EKO APARATURA, Poland). The characteristic TCBS dark yellow colonies of about $2 \mathrm{~mm}$ in diameter (V. cholerae) and blue-green colonies (V. parahaemolyticus, V. vulnificus) were extracted and purified [13, 14]. The isolated strains were stored at $-20^{\circ} \mathrm{C}$. The strains were identified by MALDI-TOF using a VITEK MS instrument (bioMérieux, France). Briefly, a portion of a bacterial colony $(\sim 1 \mu \mathrm{L})$ was transferred onto a MALDI sample plate, overlaid with $1 \mu \mathrm{L}$ of a saturated solution of $\alpha$-cyano-4-hydroxycinnamic acid in acetonitrile (28\%), and then allowed to dry at room temperature. For each isolate, a mean spectrum was constructed with at least $50 \mathrm{~m} / \mathrm{z}$ spectra profiles and used for the identification by comparison with the spectra contained in the Saramis database (bioMérieux). Identification was defined as $>99 \%$ match to the species-specific $\mathrm{m} / \mathrm{z}$ profiles in the database. Escherichia coli ATCC 8739 (bioMérieux, Marcy l'Etoile, France) was used as a standard for calibration and quality control.

\section{WET SAND SAMPLES}

Sampling. A total of 105 samples of wet sand were tested for the purpose of this study. Samples of wet sand were collected at 15 sample sites (excluding sample site 9: Chalupy - Gulfside) to aseptic plastic containers (200 mL). Wet sand was sampled in the area between the dry sand and the seawater (the intertidal zone). At each site, the sand was collected from the depth of up to $5 \mathrm{~cm}$.

Isolation and identification. All samples of wet sand were transported directly to the laboratory and isolation was performed on the day of collection. Wet sand samples were mixed and shaken with sterile deionised water $(100 \mathrm{~mL})$ for 30 minutes at the speed of 200 c.p.m. (laboratory shaker type 358 S, Elpin +) (wet sand washing water). In the next step, the wet sand washing water $(50 \mathrm{~mL})$ was filtered using $0.45 \mu \mathrm{m}$ filters. The filters were applied onto the CHROM agar Vibrio (CHROMagar, France) to pre-differentiate the obtained microorganisms. Chromogenic agar with filters were incubated at $37^{\circ} \mathrm{C}$ for $18-24$ hours (POL-EKO APARATURA, Poland). Bacteria of the genus Vibrio that grow on the chromogenic medium have a different colony colour (V. parahaemolyticus - mauve, $V$. cholerae/V. vulnificus - turquoise blue). Next, the characteristic colonies from the Vibrio chromogenic agar were transferred onto the chromogenic TCBS medium and incubated at $37^{\circ} \mathrm{C}$ for $18-24$ hours (POL-EKO APARATURA, Poland). The characteristic TCBS dark yellow colonies of about $2 \mathrm{~mm}$ in diameter ( $V$. cholerae) and blue-green colonies (V. parahaemolyticus, V. vulnificus) were extracted and purified $[13,14]$. The strains were identified by MALDI-TOF in the same way as isolates obtained from water samples (described in the Water Samples, Isolation, and Identification section).

\section{RESULTS}

The presence of $V$. vulnificus in coastal waters of the Baltic Sea was confirmed in 3 seawater samples collected in: Hel (1 isolate), Jastarnia ( 1 isolate), and Chalupy (1 isolate). The strain of Vibrio alginolyticus was found in a seawater sample collected in Hel. Moreover, the identification was incomplete for 6 of the isolated strains, these were identified as Vibrio cholerae/mimicus. The strains which were not completely identified had been collected in Jastarnia (1 isolate), Puck ( 2 isolates), Chalupy (1 isolate). The metadata associated with the isolates are presented in Table 1.

The presence of Vibrio spp. was confirmed in 2 wet sand samples collected in the Gulf of Gdansk, the samples were collected in Kuznica - Gulfside (1 isolate) and Gdansk-Brzezno (1 isolate). The identification of isolates obtained from wet sand samples was incomplete; the strains were identified as Vibrio cholerae/mimicus. The metadata associated with the isolates are presented in Table 2.

\section{DISCUSSION}

The present research is one of the first concerning the prevalence of $V$. vulnificus in coastal waters and in the wet sand at the beaches and bathing sites in the Gulf of Gdansk. A number of researchers have indicated the correlation between global warming and the prevalence of Vibrio spp. in the Baltic Sea. In 2017, Semenza et al. [5] published the results of their analysis concerning the risk of growth and spread of Vibrio spp. in the Baltic Sea and its potential for causing infections in humans. For the purpose of the research study, they used the European Centre for Disease Prevention and Control (ECDC) online tool 'Vibrio map Viewer' (https://e3geoportal.ecdc.europa.eu/SitePages/Vibrio\%20Map\%20Viewer.aspx) and the information on the prevalence of Vibrio infections (2006-2014) which is gathered and registered under the Swedish Communicable Diseases Act. Vibrio spp. have already been observed many times in the coastal waters of the Baltic Sea, and it is estimated that their presence is influenced by an increase in the temperature in the coastal regions. The presence of Vibrio spp. has been confirmed off the coast of Lithuania in 2018 [15]. V. cholerae was observed in Sweden (2003, 2004, and 2006) [2, 10]. V. vulnificus and V. parahaemoIyticus were also isolated off the coast of Germany [16]. In Poland, the presence of the Vibrio genus has as yet only been detected in the Bug river, and all the strains $(n=22)$ were identical to V. cholerae El Tor 01 Ogawa [17]. The data concerning the prevalence of Vibrio spp. in the Baltic Sea is presented in Table 3. 
Table 1. Vibrio spp. isolates obtained from the coastal waters of the Baltic Sea

\begin{tabular}{|c|c|c|c|c|c|c|}
\hline $\begin{array}{l}\text { Isolate } \\
\text { number }\end{array}$ & Identification & Sampling site & $\begin{array}{l}\text { Source of } \\
\text { isolation }\end{array}$ & $\begin{array}{l}\text { Date of } \\
\text { isolation }\end{array}$ & $\begin{array}{l}\text { Sea surface } \\
\text { temperature }\left[{ }^{\circ} \mathbf{C}\right]^{*}\end{array}$ & $\begin{array}{l}\text { Longitude } \\
\text { and latitude* }\end{array}$ \\
\hline W1 & V. vulnificus & Hel - Gulfside & Water & 15.07 .2020 & 19.2 & $\begin{array}{l}18^{\circ} 47^{\prime} \mathrm{E} \\
54^{\circ} 36^{\prime}\end{array}$ \\
\hline W2 & V. vulnificus & $\begin{array}{l}\text { Jastarnia - } \\
\text { Gulfside }\end{array}$ & Water & 15.07 .2020 & 18.5 & $\begin{array}{l}18^{\circ} 39^{\prime} \mathrm{E} \\
54^{\circ} 41^{\prime} \mathrm{N}\end{array}$ \\
\hline W3 & $\begin{array}{l}\text { V. cholerae/ } \\
\text { /mimicus }\end{array}$ & Puck & Water & 27.07 .2020 & 20 & $\begin{array}{l}18^{\circ} 24^{\prime} \\
54^{\circ} 43^{\prime}\end{array}$ \\
\hline W4 & $\begin{array}{l}\text { V. cholerae/ } \\
\text { /mimicus }\end{array}$ & $\begin{array}{l}\text { Jastarnia - } \\
\text { gate } 48\end{array}$ & Water & 10.08 .2020 & 20 & $\begin{array}{l}18^{\circ} 40^{\prime} \mathrm{E} \\
54^{\circ} 42^{\prime} \mathrm{N}\end{array}$ \\
\hline W5 & V. alginolyticus & Hel - Gulfside & Water & 10.08 .2020 & 21.3 & $\begin{array}{l}18^{\circ} 47^{\prime} \\
54^{\circ} 36^{\prime}\end{array}$ \\
\hline W6 & $\begin{array}{l}\text { V. cholerae/ } \\
\text { /mimicus }\end{array}$ & Chalupy - Gulfside & Water & 27.08 .2020 & 19.6 & $\begin{array}{l}18^{\circ} 28^{\prime} \\
54^{\circ} 46^{\prime}\end{array}$ \\
\hline W7 & V. vulnificus & Chalupy - Gulfside & Water & 27.08 .2020 & 19.6 & $\begin{array}{l}18^{\circ} 28^{\prime} \\
54^{\circ} 46^{\prime}\end{array}$ \\
\hline w8 & $\begin{array}{l}\text { V. cholerae/ } \\
\text { /mimicus }\end{array}$ & Puck & Water & 27.08 .2020 & 19.7 & $\begin{array}{l}18^{\circ} 24^{\prime} \\
54^{\circ} 43^{\prime}\end{array}$ \\
\hline
\end{tabular}

*Data on the water temperature at the sampling site was obtained from available online databases (SatBaltyk) [12]

Table 2. Vibrio spp. isolates obtained from wet sand samples

\begin{tabular}{lllll}
\hline Isolate number & Identification & Sampling site & Source of isolation & Date of isolation \\
\hline S1 & V. cholerae/mimicus & Kuznica - Gulfside & Wet sand & 29.06 .2020 \\
S2 & V. cholerae/mimicus & Gdansk-Brzezno - gate 52 & Wet sand & 14.07 .2020
\end{tabular}

Table 3. The prevalence of Vibrio spp. in the Baltic Sea

\begin{tabular}{llll}
\hline Microorganism & Coastline (country) & Year & Reference \\
\hline Vibrio spp. & Lithuania & 2018 & {$[15]$} \\
V. cholerae & Sweden & 2006 & {$[10]$} \\
V. cholerae & Sweden & $2003-2004$ & {$[2]$} \\
V. vulnificus & Germany & 2006 & {$[16]$} \\
V. parahaemolyticus & Germany & 2006 & {$[16]$} \\
V. alginolyticus & Germany & 2006 & {$[16]$}
\end{tabular}

In the last few decades, there has been an increasing number of infections caused by the bacteria of the Vibrio genus in the Baltic Sea region. Infections caused by V. cholerae (including 2 fatal cases) were recorded in Finland in 2003 [18]. Patients were reported to have been exposed to seawater. In 2006, 3 cases of wound infections by non-agglutinating and non-toxin-producing V. cholerae were reported in Sweden. All of these patients had contact with water from the Baltic Sea or the irrigation ponds. Environmental research has confirmed the presence of the above bacteria in 4 Swedish lakes [10].

It has already been mentioned that $V$. vulnificus was isolated from German patients with skin infections and septicaemia. All of the described cases were associated with seawater exposure while bathing in the Baltic Sea [8]. In August 2003, at least 2 cases of V. vulnificus infections were reported on the Island of Usedom. The analysis of the seawater in this region showed a high concentration of V. vulnificus, which was likely associated with high water temperature (exceeding $20^{\circ} \mathrm{C}$ ) [19]. Both patients had open wounds when they entered the water. It is also important to emphasize that both of them had underlying diseases. Genotypic analysis and virulence characteristics of $V$. vulnificus isolates obtained from the patients and the environment (the German coast) showed that V. vulnificus represented two distinct clusters (I and II). There was no clear distinction between clinical and environmental isolates [9]. 
Two cases of septicaemia caused by V. cholera non-01, non-0139 were reported in 2006, in Poland. The first case was seen in a male patient aged 49 years. Epidemiological investigation indicated that the transmission probably occurred while the man was swimming in a lake. Water samples collected from this water reservoir tested positive for V. cholera non-01 and non-0139. The second case involved a 79-year-old man. Epidemiological investigation indicated that the probable source of $V$. cholerae was water from an old well [20].

\section{CONCLUSIONS}

Our research study confirmed the presence of potentially pathogenic bacteria including Vibrio vulnificus in the Gulf of Gdansk in the summer months. Vibrio spp. are a group of bacteria characteristic of warm climates (tropical regions). It is estimated that the more frequent occurrence of the Vibrio bacteria in the Baltic Sea is caused by an increase in water temperature and low salinity. Climate change and global warming contribute to the creation of favourable environmental conditions for the growth and spread of these microorganisms. The presence of Vibrio spp. may become a threat to the elderly and immunosuppressed patients. Therefore, further research into the prevalence of these bacteria along the Baltic coast is necessary.

\section{FUNDING}

This work was supported by a grant from the Medical University of Gdansk (02-0108/07/780).

\section{Conflict of interest: None declared}

\section{REFERENCES}

1. Maheshwari M, Nelapati K. Kiranmayi, B. Vibrio cholerae - A review; Veterinary World. 2011; 4: 423-428.

2. Baker-Austin C, Trinanes J, Taylor NGH. Emerging Vibrio risk at high latitudes in response to ocean warming. Nature Reports Climate Change. 2012: 1-5.

3. Tamplin M. Coastal Vibrios: Identifying Relationships between Environmental Condition and Human Disease. Human and Ecological Risk Assessment: An International Journal. 2012; 7(5): 1437-1445, doi: 10.1080/20018091095113.

4. Böer SI, Heinemeyer EA, Luden K, et al. Temporal and spatial distribution patterns of potentially pathogenic Vibrio spp. at recreational beaches of the German north sea. Microb Ecol. 2013; 65(4): 1052-1067, doi: 10.1007/s00248-013-0221-4, indexed in Pubmed: 23563708.

5. Semenza JC, Trinanes J, Lohr W, et al. Environmental suitability of infections in a warming climate: an early warning system. Environ
Health Perspect. 2017; 125(10): 107004, doi: 10.1289/EHP2198, indexed in Pubmed: 29017986.

6. Vezzulli L, Pezzati E, Brettar I. Effects of global warming on Vibrio ecolog. Microbiology Spectrum - American Society for Microbiology Press. 2015: 1-9.

7. Siegel H, Gerth M (2018) Development of Sea Surface Temperature in the Baltic Sea in 2018. HELCOM Baltic Sea Environment Fact Sheets 2019. https://helcom.fi/baltic-sea-trends/environment-fact-sheets/hydrography/sea-surface-temperature-in-the-baltic-sea-in-2018/.

8. Couper AD, Mutton AFA (2019) Baltic Sea, Encyclopaedia Britannica. https://www.britannica.com/place/Baltic-Sea/Coastal-features.

9. Frank C, Littman M, Alpers A, et al. Vibrio vulnificus wound infections after contact with the Baltic Sea, Germany. Eurosurveillance. 2006; 11: 33.

10. Andersson $Y$, Ekdahl $K$. Wound infections due to Vibrio cholerae in Sweden after swimming in the Baltic Sea, summer 2006. Euro Surveill. 2006; 11(8): E060803.2, doi: 10.2807/esw.11.31.03013-en, indexed in Pubmed: 16966771.

11. Michalska M, Królska M. Surface distribution of the coliform bacteria in the Gdańsk Bay. Bulletin of the Institute of Maritime and Tropical Medicine in Gdynia. 1995: 46.

12. Ostrowska M, Darecki M, Krężel A, et al. Practical applicability and preliminary results of the Baltic environmental satellite remote sensing system (Satbałtyk). Polish Maritime Research. 2015; 22(3): 43-49, doi: 10.1515/pomr-2015-0055.

13. Oliver J, Jones J. Vibrio parahaemolyticus and Vibrio vulnificus. Chapter 66. Molecular Medical Microbiology. 2015; 2: 1169-1186, doi: 10.1016/b978-0-12-397169-2.00066-4.

14. Hounmanou YMG, Leekitcharoenphon P, Hendriksen RS, et al. Surveillance and genomics of toxigenic Vibrio cholerae 01 from fich, phytoplankton and water in Lake Victoria, Tanzania. Frontiers in Microbiology. 2019; 10(901): 1-15.

15. Gyraite G, Katarzyte M, Schernewski G. First findings of potentially human pathogenic bacteria Vibrio in the south-eastern Baltic Sea coastal and transitional bathing waters. Mar Pollut Bull. 2019; 149: 110546, doi: 10.1016/j.marpolbul.2019.110546, indexed in Pubmed: 31543486.

16. Eiler A, Johansson M, Bertillsson S. Environmental influences on Vibrio population in Northern temperature and boreal coastal waters (Baltic and Skagerrak Seas). Applied Environ Microbiol. 2006; 72: 6004-6011.

17. Stypułkowska-Misiurewicz H, Stasiak J, Janczyk M. Vibrio cholerae non-01 isolated in Poland from the river Bug. Przegląd Epidemiologiczny. 1995; 49(3): 237-243.

18. Lukinmaa S, Mattila $\mathrm{K}$, Lehtinen $\mathrm{V}$, et al. Territorial waters of the Baltic Sea as a source of infections caused by Vibrio cholerae non-01, non-0139: report of 3 hospitalized cases. Diag Microbiol Inf Dis. 2006; 54(1): 1-6, doi: 10.1016/j.diagmicrobio.2005.06.020.

19. Ruppert J, Panzing B, Guertler L. Two cases of severe sepsis due to Vibrio vulnificus wound infection acquired in the Baltic Sea. Eur J Clin Microbiol Infect Dis. 2004; 23: 912-915.

20. Stypulkowska-Misiurewicz H, Pancer K, Roszkowiak A. Two unrelated cases of septicaemia due to Vibrio cholerae non-01, non-0139 in Poland, July and August 2006. Euro Surveill. 2006; 11(11): E061130.2, doi: 10.2807/esw.11.48.03088-en, indexed in Pubmed: 17213560. 